\title{
Zanzalá
}

\section{A multiplicidade de Locating Science Fiction}

\author{
Luiz Felipe Baute ${ }^{1}$ \\ Universidade Estadual de Campinas, Brasil
}

MILNER, Andrew. Locating Science Fiction. Liverpool: University of Liverpool Press. 244 p. 2012.

Neste influente livro, o crítico cultural Andrew Milner apresenta uma sistematização engenhosa da ficção científica a partir do mapeamento de suas diversas materializações. Aliado a uma abordagem teórica influenciada, principalmente, por Raymond Williams, Pierre Bourdieu e Franco Moretti nenhum deles especialista no gênero (ainda que Williams se interessou pelo gênero) — Milner apresenta, simultaneamente, um percurso crítico da história da ficção científica e um significativo recurso analítico, configurando um novo paradigma para o estudo do gênero.

De início, o autor articula, sob o ponto de vista histórico, o desenvolvimento de formas narrativas que antecederam a ascensão da ficção científica enquanto gênero. Milner defende que as grandes mudanças sociais e culturais ocorridas no século XIX foram fundamentais para o surgimento da ficção científica. Após a Revolução Industrial, as relações entre ciência e tecnologia foram transformadas, possibilitando uma maior experimentação - e florescimento — do gênero. De antemão, o autor argumenta que a ficção científica, ao contrário do modernismo literário, é definida por seu conteúdo e não pela sua forma, sendo um gênero que privilegia, sobretudo, ideias (MILNER, 2012, p.14).

Após a exposição inicial, Milner apresenta as definições de três importantes teóricos da ficção científica: Darko Suvin, Carl Freedman e Fredric Jameson. Os trabalhos desses autores sobre o gênero são citados ao longo de todo o livro. A fim de delinear seu próprio posicionamento, Milner utiliza dos conceitos de "tradição seletiva" de Raymond Williams, e de "campo de produção cultural", de Pierre Bourdieu. Para Williams, uma tradição seletiva é formulada através de recortes intencionais de um

\footnotetext{
${ }^{1}$ E-mail para contato: 13baute@ gmail.com
} 
passado (tradição) com o objetivo de orientar um processo social e cultural específico, cuja principal função é a de identificar e definir formas, a fim de incluí-las ou excluí-las de uma determinada classificação, no presente (WILLIAMS, 1977, p. 115). Para Bourdieu, o campo de produção cultural atua em conjunto com o campo do poder, orientando os "processos de hierarquização" dos campos "heterônomo" (mais favorável ao dominante econômico e político) e "autônomo" (menos favorável ao dominante econômico e político), que atuam como formas alternativas para conferir valor à uma determinada obra artística, influenciando a sua produção (BOURDIEU, 1993, pp. 37-40). Aliado as suas primeiras referências, Milner inicia seu crescente distanciamento de Suvin, Freedman e Jameson ao argumentar contra a série de inclusões e exclusões ao cânone do gênero feita pelos autores. O crítico apresenta uma série de argumentos — com base em excertos dos trabalhos dos outros autores — para evidenciar intervenções na "tradição seletiva" da ficção científica com o objetivo de redefinir o gênero e orientar futuras produções em direção a uma poética específica do gênero. Milner admite que o argumento de Williams ao formular o conceito foi direcionado ao cânone da alta literatura arquitetada por F. R. Leavis e T. S. Eliot, no entanto, o autor defende um paralelo entre a "grande tradição" de Leavis e Eliot e a "tradição de ficção científica" de Suvin: ambas são "demasiadamente seletivas" (MILNER, 2012, p. 39). Milner, por sua vez, busca ampliar esse exercício para além do emprego acadêmico, considerando também as definições de produtores, críticos e fãs do gênero. Nesse sentido, Milner estabelece seu primeiro objetivo: derrubar a ideia de uma única tradição e, ao mesmo tempo, evidenciar a multiplicidade do gênero.

A partir de um breve debate em torno de ambos os conceitos como complementares à uma abordagem mais ampla do gênero, o autor estuda as relações entre valores econômicos e simbólicos em diversas formações culturais na história da ficção científica — incluindo uma análise de um grupo de fãs, os Futurians (MILNER, 2012, p. 60). Milner apresenta uma pesquisa ampla acerca do gênero, fazendo referência a uma grande variedade de obras de ficção científica em livros, filmes, séries, peças, histórias em quadrinhos e podcasts.

As análises feitas no capítulo 4, dedicado a produção radiofônica de ficção científica, merecem destaque, sobretudo tendo em vista a pouca produção acadêmica sobre o assunto. Segundo o autor, a negligência em relação a produção no rádio (que foi, um dia, um dos grandes expoentes do gênero) é um sintoma não apenas da descontinuidade de suas grandes produções, mas, também, de uma inadequação do meio aos modelos acadêmicos vigentes. Utilizando da teoria do Materialismo Cultural ${ }^{2}$ formulada por Williams para suas análises, Milner investiga três casos: as adaptações de Guerra dos mundos (War of the

\footnotetext{
${ }^{2}$ Williams designa o Materialismo Cultural da seguinte maneira: "Uma teoria da cultura como um processo produtivo (social e material) e de práticas específicas, de 'artes', como usos sociais dos meios materiais de produção (desde a linguagem como 'consciência prática' material até as tecnologias específicas da escrita e formas da escrita, através de sistemas de comunicação mecânicos e eletrônicos).” (WILLIAMS, 2005, p. 243). Todas as traduções são de minha autoria.
} 
worlds, H.G. Wells, 1938) e O estado da arte (The State of the Art, dir. Nadia Molinari, 2009), e a peça Das Unternehmen der Wega ${ }^{3}$ (Friedrich Dürrenmatt, 1958). Efeitos imersivos como estranhamentos espaciais e temporais, experimentalismos sonoros e, sobretudo, a centralidade do diálogo nas produções, são vistos como fatores que privilegiam aspectos inerentes da ficção científica, além de reforçar o pressuposto do gênero como uma forma que prima por ideias (MILNER, 2012, p. 81). Porém, o autor defende que a chave para o entendimento da ficção científica para o rádio está na tensão entre, de um lado, as convenções do gênero e, de outro, a materialidade e linguagem do meio. Segundo o autor, o desenvolvimento dessa relação promoveu a exploração de mercados de nicho em detrimento a grandes produções, resultando no desaparecimento do meio no campo de produção mais heterônomo da ficção científica (MILNER, 2012, p. 88). De um modo geral, a contribuição de Locating Science fiction é feita nesses primeiros passos de uma análise, na intersecção entre meio e forma, indicando obras diversas no campo de produções expandido do gênero e oferecendo uma metodologia passível de ser utilizada em futuras pesquisas (MILNER, 2012, p. 87-88).

Os capítulos seguintes, dedicados as relações entre ficção científica, utopia e distopia, oferecem uma boa introdução ao debate e podem ser utilizados para fins didáticos. Milner afirma que a visão dominante nos estudos de ficção científica norte-americanas, sobretudo nas linhas de Suvin e Jameson, designam a utopia como um subgênero da ficção científica (MILNER, 2012, p. 91). Freedman e Phillip Wegner fazem apontamentos similares. Para todos, a proposta é inspirada pelo livro $O$ princípio da esperança, de Ernst Bloch. Ademais, o estudo de Bloch foi referência para Suvin na elaboração do conceito de novum ${ }^{4}$. Williams, por sua vez, dispensa periodizações tais quais as dos autores citados, ainda que insista na relação (separadas conceitualmente) entre ficção científica e utopia (MILNER, 2012, p. 97).

Milner segue, mais uma vez, um caminho similar a Williams em relação a utopia, em direção a uma análise explicativa em detrimento a uma delimitação do gênero (MILNER, 2012, p. 103-106). Porém, em relação a distopia, sobretudo em uma variação definida como distopia crítica, Milner apresenta uma incomum defesa. Tanto Williams quanto Jameson alertaram sobre os perigos de uma densidade excessiva em narrativas distópicas, causando uma espécie de estase social, contrária a uma ideia de resistência. Através de um exame de 1984 de George Orwell — alvo de críticas tanto de Williams quanto de Jameson - Milner desenvolve uma análise mais positiva. O autor vê a obra de Orwell como uma tentativa de alertar sobre a possibilidade de ascensão do totalitarismo e que, apesar de seu presente narrativo ser sombrio, o final indica uma resolução favorável à resistência: o apêndice que conclui a narrativa, escrito na terceira pessoa, revela que o regime do Grande Irmão acabou. Desse modo, Milner

\footnotetext{
3 “A companhia de Vega" em uma tradução livre. A peça não foi publicada no Brasil.

${ }^{4}$ Suvin designa o novum como um conceito-chave para distinguir a ficção científica de outras narrativas. Segundo o autor, a ficção científica é definida como um gênero por possuir a "dominância ou hegemonia de um "novum" (novidade, inovação) ficcional validado pela lógica cognitiva” (SUVIN, 1979, p. 63).
} 
constata que 1984 foi "escrito, ao menos em parte, exatamente como inspiração a resistência política que Williams e Jameson insistem que não pode ser.” (MILNER, 2012, p. 122).

Em seguida, o autor reforça que produções de ficção científica utópicas trabalharam, necessariamente, em diferentes registros político-filosóficos, influenciados pelas convenções literárias e audiovisuais de seu tempo. Já as produções distópicas, ainda que sujeitas as mesmas influências, destacam-se, prioritariamente, pelo aspecto de alerta. A grande questão para as distopias críticas, para o autor, gira em torno da criação, plausível, de um espaço verdadeiramente ameaçador sem ser desmoralizante (MILNER, 2012, p. 127).

Com o objetivo de apresentar a sua proposta analítica, Milner direciona a problemática para a localização (geográfica e temporal) da ficção científica. A proposta do crítico gira em torno de uma reconfiguração teórico-metodológica do gênero, ampliando as suas tênues fronteiras sem se perder em uma falsa homogeneidade. Milner ancora a sua proposta argumentando que a tradição seletiva do gênero está concentrada em autores como Wells, Jules Verne e Mary Shelley não apenas por conta de seus textos seminais, mas, também, por conta da posição cultural destacada de seus países. Segundo o autor, após a expansão mundial da ficção científica, torna-se necessário reavaliar e mapear o gênero como um todo. Para tanto, Milner utiliza das contribuições de Franco Moretti e Immanuel Wallerstein.

A teoria do sistema-mundo de Wallerstein divide os países do globo entre: centrais, semiperiféricos e periféricos. As definições são inter-relacionais, envolvendo processos produtivos que sustentam uns aos outros em desenvolvimentos desiguais e combinados. Franco Moretti adapta esse modelo em seus estudos literários, observando um "sistema de variações" no romance moderno, no qual o centro (inglês e francês), tende a uniformidade, enquanto o periférico e semiperiférico (todo o restante) à diferença. Por meio da disputa entre ambas, surgem variações na própria forma das obras, em acordo com a prerrogativa do gênero como uma formação em constante mudança (MORETTI, 2000, p. 55-57). Um alerta importante à essa teoria, bem como uma evasão de Milner, é o perigo de uma definição tautológica do semiperiférico. Se a evidência para a classificação do semiperiférico é o comparativo criativo e cultural, não é possível utilizar o semiperiférico para explicar o comparativo criativo e cultural. Milner evita essa questão indicando que existem outras formas de distinguir entre o periférico e o semiperiférico. No entanto, o autor não as indica, afastando-se um debate em torno dessas especificidades (MILNER, 2012, p. 166).

Como ilustração de sua metodologia, Milner analisa a transição japonesa de uma condição semiperiférica para o centro a partir da expansão do gênero no país após a ocupação estadunidense. Segundo o autor, o Japão retrabalhou a exportação ocidental e redefiniu seus próprios paradigmas através de trabalhos de grande influência para o gênero no país e no mundo todo como Godzilla (dir. Ishiro Honda, 1954), Cyborg 009 (Shotaro Ishinomori, 1964-1981), Astro boy (Ozamu Tezuka, 1952-1968), entre outros (MILNER, 2012, p. 175-176). A partir desse estudo de caso, Milner afirma, em oposição a 
abordagem dos estudos pós-coloniais, que a produção japonesa tem mais relação com o posicionamento do país em relação a tecnologia do que com o seu passado imperialista. Ainda que Milner reconheça a contribuição dos estudos pós-coloniais, o crítico defende que a teoria do sistema-mundo fornece uma posição teórica mais persuasiva (MILNER, 2012, p. 176). É possível interpretar esse posicionamento como uma tentativa de exercer influência acadêmica, argumentando em favor da versatilidade de sua teoria, abrindo caminho tanto para os estudos marxistas, feministas e queer quanto para os pós-coloniais (MILNER, 2012, p. 160). Milner atesta que, apesar das críticas de ocidentalismo à teoria do sistemamundo, ela pode funcionar para diversos tipos de análises e convida teóricos de outras localizações mais periféricas (como a sua Austrália), citando especificamente a América Latina, a desenvolverem análises (MILNER, 2012, p. 177).

Após essa retomada, Milner volta a criticar os usos prescritivos da ficção científica, sejam eles de cunho formal e estético, político ou, mais comumente, uma combinação dos dois. (MILNER, 2012, p. 178). No entanto, após muitos embates, Milner adota uma posição mais amistosa, ao alertar que sua intenção não foi a de repelir pensamentos políticos no gênero, nem de relativizar toda e qualquer prática, mas alegar que predefinir o conteúdo de uma disciplina, como os estudos de ficção científica, através de valores políticos ou estéticos pode não fazer jus as suas muitas manifestações (MILNER, 2012, p. 179).

Em seguida, Milner parte para análises de duas obras (ambas australianas) que estão alinhadas com seus trabalhos mais recentes acerca das relações entre a ficção científica e as mudanças climáticas: A hora final (On the beach, Nevil Shute) e The sea and summer ${ }^{5}$ (George Turner). Milner defende que ambas as distopias funcionam, efetivamente, como "utopias de aviso" (MILNER, 2012, p. 186) acerca da questão ambiental e conclui o livro com um convincente discurso sobre a necessidade de criação de novas formações para a ficção científica, capazes de estabelecer um cenário verdadeiro, ameaçador e instigante do presente como, também, uma imaginação utópica — implícita ou explícita — para o futuro.

A leitura de Locating science fiction é desafiadora e estimulante, auxiliando na imaginação de novas possibilidades para a ficção científica apesar da pouca profundidade de suas análises. Por meio de seu distanciamento do formalismo de Suvin, o autor revela outras (relevantes) abordagens para o gênero. Milner considera o gênero não como um conjunto de categorias inertes, mas como uma forma cultural em constante transformação. Ademais, a defesa dos espaços periféricos e semiperiféricos do gênero como produtores relevantes é um dos aspectos de maior envergadura do estudo, ainda mais considerando a ficção científica como um tipo de narrativa em disputa contínua. A maior contribuição do estudo de Milner está na exposição de uma metodologia abrangente e flexível para diversos projetos acadêmicos, apresentando ferramentas pertinentes para pesquisadores da ficção científica e outros gêneros.

\footnotetext{
${ }^{5}$ Romance não publicado no Brasil.
} 


\section{Referências}

BOURDIEU, Pierre. The Field of Cultural Production: Essays on Art and Literature. Nova Iorque: Columbia University Press. 1993.

MORETTI, Franco. The Way of the World: The Bildungsroman in European Culture. Londres; Nova York: Verso, 2000.

SUVIN, Darko. Metamorphoses of science fiction: on the poetics and history of a literary genre. New Haven: Yale University Press. 1979.

WALLERSTEIN, Immanuel. World-systems analysis: an introduction. Durham: Duke University Press. 2004.

WILLIAMS, Raymond. Culture and Materialism. Londres: Verso. 2005 . Marxism and Literature. Oxford: Oxford University Press, 1977. 